DOI 10.37882/2223-2982.2020.07-2.31

\title{
ИСТОРИЯ АТОМНЫХ ПОДВОДНЫХ ЛОДОК ТИХООКЕАНСКОГО ФЛОТА
}

\section{HISTORY OF NUCLEAR SUBMARINES OF THE PACIFIC FLEET}

\section{Semenov}

Summary: About the nuclear submarine fleet of the USSR has been written, but the relevance of the article is that the author showed the dynamics of development (history) of nuclear submarines in the Pacific fleet: composition, tasks and basing of nuclear submarines. The author showed how with the growth of scientific and military-technical achievements, the combat capabilities of submarines' weapons grew, and the range of tasks they solved expanded. As a conclusion: nuclear submarines were the main strike force of the Pacific fleet, which in 1970 1990 solved the problem of ensuring the security of the USSR in the AsiaPacific region.

Keywords: USSR Pacific Fleet, nuclear submarines with ballistic missiles, nuclear submarines with cruise missiles, multipurpose nuclear submarines, combat capabilities, quantity.
$\mathrm{B}$ конце 1956 г. Главнокомандующий Военно-морского флота СССР С.Г. Горшков выступил с докладом о приоритетном развитии подводных сил, что по его мнению, «...позволяло в кратчайшие сроки резко увеличить ударные возможности флота и с меньшей затратой средств умножить морское могущество нашей страны». Приоритет всех дальнейших кораблестроительных программ постоянно отдавался подводным лодкам, а среди них - атомным подводным лодкам с баллистическими ракетами стратегического назначения, что позволило создать морскую стратегическую систему, достигнув в этой области к середине 1970-х годов примерного паритета с США[1, с. 6].

Атомные подводные лодки (АПЛ) были способны вести боевые действия в любых районах Мирового океана, при этом были способны наносить мощные ракетно-ядерные удары по важным в военном отношении объектам противника и наиболее эффективно вести боевые действия против боевых надводных кораблей, подводных лодок, транспортов и судов противника, и обладали перед надводными силами и авиацией таким преимуществом, как скрытность. В XX-м веке в нашей стране было построено 249 АПЛ - это больше, чем во всех странах мира.

В составе ВМФ СССР было 4 поколения атомных подводных лодок:

\author{
Семёнов Виктор Николаевич \\ К.т.н., докторант, Дальневосточный федеральный \\ университет, Владивосток \\ viktor_55@mail.ru
}

Аннотация: 06 атомном подводном флоте СССР написано много, но актуальность статьи заключается в том, что автор показал динамику развития (историю) атомных подводных лодок на Тихоокеанском флоте: состав, решаемые задачи и базирование атомных подводных лодок. Автор показал, как с ростом научных и военно-технических достижений росли боевые возможности вооружения подводных лодок, расширялся круг решаемых ими задач. Как вывод: атомные подводные лодки являлись главной ударной силой Тихоокеанского флота, который в 1970-1990 гг. решал задачу обеспечения безопасности СССР в Азиатско-Тихоокеанском регионе.

Ключевые слова: Тихоокеанский флот СССР, атомные подводные лодки с баллистическими ракетами, атомные подводные лодки с крылатыми ракетами, многоцелевые атомные подводные лодки, боевые возможности, количеств0.

- 1-е поколение (проекты 627, 645, 658, 659, 675). Характерные черты - двух-вальная энергетическая установка с двумя реакторами, недостатки - повышенная шумность и значительная пожароопасность, по эффективности ракетного оружия первые советские подводные лодки уступали американским;

- 2-е поколение (проекты 667, 670, 671, 705). Попрежнему советские подводные лодки оставались более шумными, чем американские, однако у нас их было значительно больше: в СССР в 70-е гг. было спущено на воду в 3 раза больше подводных лодок, чем в США;

- 3-е поколение $(945,685,949,871,941)$, характеризуется повышенной скрытностью за счёт увеличения глубины погружения и снижения уровня шума;

- 4-е поколение $(885,955)$ по совокупности характеристик не уступало современным зарубежным аналогам [3, с. 3].

60-е годы XX-го века для Тихоокеанского флота (ТОФ) стали годами начала создания океанского, ракетноядерного флота.

Началу строительства атомного подводного флота Советского Союза положило Постановление Совета министров СССР от 09.09.1952 г. № 4098-1616 «О проекти- 
ровании и строительстве объекта № 627», подписанное Сталиным ещё в 1952 г. [9], но история АПЛ ТОФ началась в 1961 г. с поступлением в состав флота атомной подводной лодки с крылатыми ракетами (АПЛРК) проекта 659.

Изначально атомные подводные лодки (АПЛ) задумывались, как торпедные, однако принятие на вооружение противокорабельных ракет, стартующих из штатных торпедных аппаратов, придало этим подводным лодкам противокорабельные качества. После оснащения их стратегическими крылатыми ракетами для поражения береговых объектов они в полном смысле стали многоцелевыми.

Всего на ТОФ было 36 АПЛРК трёх поколений: первое поколение лодок представляли 19 АПЛ: 5 - проекта 659 (Echo-I)* 14 - пректа 675 (Echo-II)*; второе поколение представляли 11 АПЛ проекта 670 (Charlie-I)*; третье поколение представляли 6 АПЛ проекта 949A (Oscar-II)*. *по классификации НАТО.

АПЛРК 659 проекта были спроектированы в ЦКБ-18 (главный конструктор П.П. Пустынцев), 5 единиц были построены (1961-1963 гг.) в г. Комсомольск-на-Амуре на СС3 №199. На вооружении они имели 6 крылатых ракет П-5 с ядерной боевой частью, максимальная дальность стрельбы 350 км. Для того чтобы осуществить пуск всех 6 ракет, АПЛРК с момента всплытия в надводное положение требовалось около 12,5 минут - слишком мало для того, чтобы противолодочные силы нашли её в огромных просторах океана, пусть даже и ограниченных дальностью полёта ракеты П-5 районах. Принятые в состав флота АПЛРК проекта 659 позволили расширить не только круг задач, но и районы действия подводных лодок. В зону досягаемости ракет находились цели на западном побережье США. Из-за низкой эффективности ракет П-5, в ранге стратегических ракетоносцев лодки проекта 659 находились недолго. Постройку последней АПЛРК проекта 659 завершили в июле 1963 г., а уже в декабре 1963 г. было принято решение о её переоборудовании в торпедную лодку по проекту 659T. Дальнейшего развития специализированные подводные лодки с крылатыми ракетами для стрельбы по берегу тогда не получили ибо эта задача была полностью возложена на подводные лодки с баллистическими ракетами.

17 августа 1956 г. вышло постановление Совета министров СССР о начале проектирования АПЛРК проекта 675, а уже в 1964 г. они стали поступать в состав ТОФ. Создавались они на базе АПЛРК проекта 659, но вооружаллись новыми противокорабельнылми ракетами П-6. Старт ракет осулществлялся в надводном положелнии из поднимавшихся на угол $14^{\circ}$ транспортно-пусковых контейнелров. После всплытия подводной лодки в надводное положение на предстартовую подготовку до пуска первой ракеты первого залпа тре- бовалось три минуты. Второй 4-х ракетный залп мог производиться через 12 минут. Атомоход мог выполнить 4-х ракетный залп в течение 15 минут, два залпа - за 20-30 минут. Обеспечивалась возможность одновременного обстрела цели 12 ракетами П-6 с различных носителей, что позволяло преодолевать самую плотную противовоздушную оборону авианосных соединений 60-х годов. На АПЛРК проекта 675 впервые в мире была реализована возможность залповой ракетной стрельбы с избирательным поражением кораблей противника, находящихся в составе соединений. Для стрельбы крылатыми ракетами впервые в мире была создана разведывательно-ударная система, включающая авиационную разведывательную систему «Успех», которая обнаруживала морские цели и передавала сигналы на подводную лодку, где осуществлялась обработка данных и выдавались целеуказания ракетному комплексу [7, с. 44]. АПЛРК проекта 675 была предназначена для нанесения ударов по морским и береговым целям при военных действиях на морских коммуникациях. В составе ТОФ было 14 таких АПЛ и прослужили они более 20 лет. 8 АПЛРК проекта 675 были модернизированы по проекту 675МК: на них противокорабельные ракеты комплекса П-б были заменены на крылатые ракеты комплекса «П-500» («Баᄀзальт»). Также была установлена аппаратура системы приёма космического целеуказания «Касатка-Б», а система «Аргон-К» соᄀвместно с системой предстартовой подготовки крылатой ракеты обеслпечивали залповую стрельбу всеми ракетами. 1 АПЛРК проекта 675 была модернизирована по проекту 675МКВ: на ней были установлены новый ракетный комплекс «Вулкан», обладающий значительно увеличенной дальностью стрельбы, и современный гидроакустический комплекс «Керчь».

В 1974 г. в состав ТОФ начали поступать АПЛРК проекта 670 шифр «Скат», разработанные ЦКБ «Лазурит» под руководством В.П. Воробьёва. Они были первыми серийными АПЛ, вооружёнными противокорабельными крылатыми ракетами оперативного назначения с подводным стартом «Аметист». Эти ракеты могли стартовать с глубин до 30 м, при скорости хода носителя не более 5,5 уз и волнении моря до 5 баллов, при дальности стрельбы около 80 км имели низкую траекторию полёта (около 50 - 60 м) и могли автоматически выбирать самую крупную цель в ордере. В случае необходимости ракета поражала цели избирательно [1, с. 47]. Эти АПЛРК были построены в г. Горький на заводе «Красное Сормово им. А.А. Жданова». На ТОФ первая лодка прибыла в 1974 г., а затем, в течение 12 лет (1977-1988 гг.), прибыло ещё 10 ед. Основной задачей АПЛРК проекта 670 было слежение (при получении приказа - уничтожение) за американскими авианосцами. Небольшая дальность стрельбы требовала преодолевать дальнюю зону противолодочной обороны авианосной ударной группы, чтобы выйти на рубеж применения противокорабельных ракет. Благодаря относительно малому водоизмещению и не- 
высокой шумности, лодка решала задачу скрытности. В связи с нехваткой на ТОФ противолодочных подводных лодок привлекались для решения задач по поиску американских ПЛ в районах боевого патрулирования наших ракетных подводных лодок стратегического назначения. В начале 90-х все подводные лодки проекта 670 были выведены и боевого состава.

Дальнейшее развитие АПЛРК пошло по пути создания лодок, вооружаемых крылатыми ракетами большой дальности, которые официально начали классифицироваться как противокорабельные ракеты «оперативного назначения» [6, с. 67]. АПЛРК проекта 949А (шифр «Антей») были разработаны ЦКБ МТ «Рубин» под руководством П.П. Пустынцева, а затем И.Л. Баранова. На вооружении подводная лодка имела сверхзвуковые крылатые ракеты комплекса П-700 «Гранит» с максимальной дальностью стрельбы 550 км, снаряжённая как ядерной (500 Кт), так и фугасной боевыми частями массой 750 кг [7, с. 50]. Подводные лодки данного типа были предназначены для самостоятельного и во взаимодействии с другими силами ВМФ нанесения ударов крылатыми ракетами и торпедами по крупным надводным кораблям и судам противника, следующим в составе авианосно-ударной группы или конвоев. Противокорабельный ракетный комплекс «Гранит» обеспечивал сравнительно высокую вероятность поражения авианосцев, следующих в составе корабельных соединений с сильными противовоздушной и противоракетной обороной. Однако использование «Гранит» было затруднено из-за отсутствия эффективной системы целеуказания. Оно могло быть получено от системы морской космической разведки и целеуказания (МКРЦ) «Легенда» или разведывательных самолётов Ту-95РЦ, которые с началом боевых действий, вероятнее всего, были бы либо сбиты, либо подавлены, а использование собственного радиотехнического вооружения для целеуказания на полную дальность стрельбы было невозможно [1, с. 57]. АПЛРК проекта 949А были построены в г. Северодвинск на «Северном машиностроительном предприятии», первая лодка проекта 949А прибыла на ТОФ в1990 г., к 1998 г. их было уже 6.

В 1963 г. в состав ТОФ прибыла новая по своему боевому предназначению АПЛ - атомная подводная лодка с баллистическими ракетами (АПЛРБ). АПЛРБ предназначены для решения военно-политической задачи ядерного сдерживания. В составе ТОФ в разное время было 35 АПЛРБ 4-х поколений: 1-е поколение - 2 АПЛ проектов 658, 658A (Hotel-I, -II) *; 2-е поколение - 12 АПЛ проектов 667А шифр «Навага», 667АУ шифр «Налим» (Yankee-І) * и 9 АПЛ проекта 667Б шифр «Мурена» (Delta-I)*; 3-е поколение - 10 АПЛ проекта 667БДР шифр «Кальмар» (DeltaIII) *; 4-е поколение - 2 АПЛ проекта 955 «Борей» («Borei») *. *по классификации НАТО.

Первой на ТОФ АПлРБ была крейсерская подводная лодка проекта 658 (К-178), которая вошла в состав ТОФ в 1963 г. Лодка имела на вооружении ракетный комплекс Д-2 с 3 баллистическими ракетами Р-13 с надводным стартом. В 1967 г. подводная лодка была модернизирована по проекту 658М: на ней был установлен новый ракетный комплекс Д-4 с ракетой Р-21, которая имела дальность полёта 1400 км и подводный старт. По сравнению с американским аналогом первый советский ракетный атомоход обладал более высокой скоростью подводного и надводного хода, а также лучшей боевой живучестью, уступая американскому ракетоносцу по уровню скрытности. АПЛРБ была предназначена для нанесения ядерных ракетных ударов по портам, военно-морским базам, административным и промышленным центрам, расположенным не только на побережье, но и в глубине территории [2]. Вторая АПЛРБ проекта 658М прибыла на ТОФ в 1968 г.

В течение семи лет (1967-1974 гг.), на заводах Северодвинска и Комсомольска-на-Амуре для ВМФ СССР была построена самая большая серия (34 ед.) ракетных крейсеров проекта 667А, 667АУ (разработан ЦКБ МТ «Рубин» под руководством С.Н. Ковалёва), имеющих 544 пус ᄀковые установки. Иными словами, группировка могла нести на борту 544 ядерных боезаряда, что составляло $22 \%$ общего числа боезарядов СССР в тот период. Таким образом, к 1974 г. в СССР была создана мощная ударная подсистема Морских стратегических ядерных сил, сопоставимая с американской системой «Polaris». ВМФ СССР предпринял энергичᄀные меры по освоению стратегических ракето ᄀносцев, отработке их боевого применения [5, с. 1030].

АПЛРБ проекта 667А была вооружена ракетным комплексом Д-5 с 16 баллистическими ракетами Р-27, которые имели дальность стрельбы 2400 км, стрельбу выполняла только в подводном положении при волнении моря до 5 баллов [1, с. 9]. Это была лодка совершенно новой конструкции: малошумная (по сравнению с АПЛРБ проекта 658), с мощной энергетикой, позволяющей развивать скорость хода до 27 узлов. В состав ТОФ в 19701972 гг. вошли 7 АПЛРБ проекта 667А.

Следующим проектом АПЛРБ был проект 667АУ - модификация проекта 667А и в отличие от него вооружался ракетным комплексом Д-5У с баллистической ракетой Р-27У, обладавшими увеличенной до 3000 км дальностью стрельбы и разделяющейся головной частью. Однако незначительные точность и дальность стрельбы баллистическими ракетами комплексов Д-5 и Д-5У вынуждали АПРБ проектов 667А, 667У оперировать у берегов США, в районах активности противолодочной обороны вероятного противника [1, с. 11]. Вместе с тем корабли данного типа обладали большой шумностью и низким коэффициентом оперативного напряжения. Всего на ТОФ было 12 АПЛРБ 667А и 667АУ (7 - проекта 667А 
и 5 - проекта 667АУ), и прослужили они в боевом составе флота до начала 90-х гг.

Ещё не закончили поступать в состав ВМФ СССР АПЛРБ проекта 667АУ, а в 1972 г. в состав ВМФ вошла первая АПЛРБ проекта 667Б, которая была разработана ЦКБ МТ «Рубин» под руководством С.Н. Ковалёва. Боевая эффективность АПЛРБ проекта 667Б была в 2.5 раза выше, чем у АПЛРБ проекта 667А. Она была вооружена ракетным комплексом Д-9 с 12 двухступенчатыми межконтинентальными баллистическими ракетами Р-29, дальность полёта которых составляла 7800 км. При такой дальности стрельбы сталло возможным нести боевое патрулирование на малошумных скоростях в прибрежных морях и территориальных водах, а широкий сектор обстлрела позволял запускать ракеты с базы от причалла. Таким образом, появилась возможность нести боевое дежурство в готовности к применению ракетного оружия при стоянке в пункте базирования. Этим обеспечивались не только защита и оборона ралкетоносцев от сил противолодочной войны США и НАТО, но и гарантировалось уверенное управ лление ракетными крейсерами в море [5, с. 1031]. В состав ТОФ (1975-1978 гг.) вошли 9 АПЛРБ проекта 667Б. Начиная с 1976 г. они несли боевую службу - боевое дежурство в районах, находящихся на относительно небольшом удалении от берегов Камчатки. В 1993 г. АПЛРБ проекта 667Б начали выводить из боевого состава ТОФ, и до конца 90-х в составе флота их уже не было.

Для размещения новой двухступенчатой жидкостной баллистической ракеты Р-29Р Д-9Р в ЦКБ МТ «Рубин» под руководством С.Н. Ковалёва был разработан новый проект ракетного подводного крейсера - проект 667БДР. Система управления стрельбой позволяла выстреливать весь ракетный боекомплект в одном залпе, с сокращёнными интервалами между пусками. Главной особенностью комплекса Д-9Р являлось то, что существовало три взаимозаменяемых варианта головных частей ракет. Ракета Р-29P несла разделяющуюся головную часть с 3 боевыми блоками мощностью по 0,2 Мт и обладала максимальной дальностью полёта 6500 км, Р-29РЛ была оснащена моноблочной головной частью мощностью 0,45 Мт и обладала максимальной дальностью полета 9 000 км, Р-29PК несла разделяющуюся головную часть с 7 блоками мощностью но 0,1 Мт и обладала максимальной дальностью полета 6500 км [1, с. 27]. В 1979-2008 гг. совершив межфлотские переходы с СФ в состав ТОФ вошли 10 АПЛРБ проекта 667БДР.

В боевом составе ТОФ проходят службу также 2 АПЛРБ проекта 955 «Борей».

Нужно отметить, что из 35 АПЛ с баллистическими ракетами

- 18 (51\%) были построены на судостроительном за- воде им. Ленинского комсомола в г. Комсомольскна-Амуре (проекта 667А - 5 ед., проекта 667АУ - 5 ед., проекта 667Б - 8 ед.);

- 12 ед. (34\%) прибыли на ТОФ, совершив переход подо льдами Арктики (проекта 658 - 2 ед., проекта 667БДР - 8 ед., проекта 955 - 2 ед.);

- 5 (14\%) прибыли на ТОФ, совершив переход с СФ южным маршрутом (проекта 667А - 2 ед., проекта 667Б - 1 ед., проекта 667БДР - 2 ед.).

Не менее важную роль в борьбе на море играли многоцелевые АПЛ, которых в составе ТОФ в разное время было 24 3-х проектов: 671B «Ёрш» (Victor-I)*, 671PTM «Щука» (Victor-III)*, 971 «Щука-Б» (Akula)*. * - по классификации НАТО.

3 многоцелевые АПЛ проекта 671В были построены в г. Ленинград на СС3 №196 «Судомех» и получили на вооружение противолодочный ракетный комплекс «Вьюга». На них был установлен гидроакустический комплекс «Рубикон». С 1974 по 1976 гг. в состав ТОФ прибыли 3 многоцелевые АПЛ проекта 671В. Из боевого состава флота они были выведены в 1989, 1993, 1994 гг.

В 1979-1984 гг. были построены и вошли в состав ТОФ 13 многоцелевых АПЛ проекта 671РТМ. Создание В нашей стране АПЛ проекта 671РТМ практически совпало с началом строительства американских многоцелевых атомных подводных лодок 3-го поколения типа SSN-688. На вооружении наших АПЛ были установлены малоразмерные дозвуковые крылатые ракеты «Гранат» с максимальной дальностью стрельбы 3000 км, а также противолодочные управляемые ракеты 83Р, 84P противолодочного ракетного комплекса «Водопад» или ракеты M5 (сверхскоростная подводная ракета, развивающая 200 узлов, при дальности хода 11 км) противолодочного комплекса «Шквал» [7, с. 14]. Новое вооружение расширяло возможности его применения не менее чем в 2.5 раза, а степень поражения в 2.5-4 раза. Новые американские АПЛ по-прежнему превосходили советские аналоги по уровню скрытности и характеристикам гидроакустического комплекса. Однако этот разрыв, по признанию самих американцев, значительно сократился и больше не носил прежнего «драматического» характера. В целом подводные лодки 671PTM и SSN-688 являлись приблизительно равноценными [7, с. 15]. АПЛ проекта 671РТМ прослужили в составе ТОФ 16-19 лет.

В 1985 г. в состав ТОФ стали поступать новые многоцелевые АПЛ проекта 971 и до 1996 г. на флоте их стало 7 ед. Эти лодки обладали высокой скрытностью и боевой устойчивостью, что давало возможность успешно преодолевать противолодочные рубежи, а также противодействие противолодочных сил. Их вооружение позволяло им бороться с подводными лодками и надводными кораблями, а также с высокой точностью поражать 
наземные объекты крылатыми ракетами. В случае вооружённого конфликта каждая лодка 971 проекта была способна создать угрозу и сковать значительную группировку противника, не допуская нанесения ударов по нашей территории [7, с. 27].

В составе ТОФ было 4 атомные торпедные подводные лодки проекта 627А. Они были построены на «Северном машиностроительном предприятии». Первая АПЛ проекта 627А вошла в состав СФ в 1959 г., и только через 4 года - в 1963 г. на ТОФ прибыла первая АПЛ проекта 627A, совершив переход подо льдами Северного Ледовитого океана. В 1966 г. АПЛ проекта 627А К-14 совершила переход подо льдами Арктики, проложив трассу, по которой в дальнейшем осуществлялась перегонка атомоходов европейской постройки на ТОФ [7, с. 5]. С 1963 по 1968 гг. на ТОФ прибыли 4 АПЛ проекта 627А, которые прослужили в боевом составе до 1990 г.

В 80-е годы благодаря ВМФ СССР и его ударной силе - подводным силам в Мировом океане было достигнуто военно-стратегическое равновесие между США и СССР. Важную роль в достижении этого военно-стратегического паритета сыграл ТОФ СССР, так как зона его ответственности составляет 50\% площади мирового океана, а глубина зоны возможных боевых действий достигает 13000 км. ТОФ все эти годы решал задачу обеспечения безопасности СССР в Азиатско-Тихоокеанском регионе: с нарастанием угрозы росло напряжение сил флота, интенсивнее неслась боевая служба кораблей и подводных лодок.

К 1989 г. ВМФ СССР по количеству подводных лодок занимал первое место в мире, при этом было 79 ракетных подводных лодок, из которых 38 атомных подводных лодок числилось на СФ, 26 атомных - на ТОФ. В составе ВМФ СССР ещё находились дизельные подводные лодки с баллистическими ракетами: 2 - на СФ, 7 - на ТОФ, 6 - на БФ, но они были уже морально устаревшими и не влияли на боевой потенциал Морских стратегических ядерных сил.

На 1 января 1989 г. в боевом составе ТОФ было подводных лодок - 117 единиц (50 \% от ВМФ), из них

- АПЛРБ - 24, что позволяло планировать патрулирование ракетных подводных крейсеров стратегического назначения в любом районе Мирового океана и находиться на дистанции применения баллистических ракет по стратегическим объектам на территории противника;

- АПлРК -21, что позволяло осуществлять скрытно поиск и длительное слежение за авианосно-ударными группами Военно-морских сил США на удаление от побережья СССР, превышающем рубеж подъёма истребительной авиации и выполнения других задач, стоящих перед авианосными соеди- нениями ВМС США. Не все они отвечали требованиям времени, но подводники отрабатывали всё новые и новые тактические приёмы, которые позволяли им решить поставленные задачи;

- многоцелевых АПЛ - 26.

В 1989 г. началось численное сокращение подводных сил ТОФ (общая тенденция для ВМФ СССР). В составе ТОФ числилось 90 подводных лодок, из них: ракетных подводных крейсеров стратегического назначения - 24, атомных (с крылатыми ракетами, многоцелевых) - 37.

С развалом в 1991 г. СССР и со сменой общественнополитической формации в России в течение нескольких лет распался океанский атомный флот: списаны на металлолом сотни кораблей, даже не выслуживших установленные сроки нахождения в боевом составе.

АПЛ ТОФ входили в состав 10 дивизий, которые базировались

А. на Камчатке:

- 45-я дивизия (1962-1998 гг.), через дивизию прошло 36 АПЛ 4 проектов;

- 10-я дивизия, была образована в 1967г., здесь проходили службу 51 АПЛ 10 проектов;

- 8-я дивизия (1970-1991 гг.). За 21 год в состав бригады входили 20 АПЛ;

- 42-я дивизия (1988-1992 гг.). За 4 года в состав дивизии входили 14 подводных лодок 3 проектов;

- 25-я дивизия (была образована в октябре 1973 г. в соответствии с директивой Главного штаба ВМФ СССР от 5 февраля 1973 г.) [10, с. 52]. За 35 лет (1932008 гг.) подводники соединения освоили 3 проекта АПЛ, выполнили 246 боевых служб и произвели 153 ракетных пуска $[10,58]$.

Б. в Приморье

- 21-я дивизия (1977- 1994 гг.) [ЦАМО АО ТОФ. Д. ф. 2082, л. 1], в состав дивизии входила 21 АПЛ 6 проектов;

- 26-я дивизия (1961-2000 гг.) - первая дивизия АПЛ ТОФ, в состав дивизии в разные годы входили 17 АПЛ 6 проектов;

- 29-я дивизия была сформирована в 1961 г., в 1971 г. перешла в Приморье, а в 1979 г. в состав дивизии вошли 9 АПЛ 675 проекта, которые прослужили в составе дивизии 12 лет;

\section{В. в зал. Советская Гавань}

- 28-я дивизия (1982-1990 гг.) в состав входили 6 АПЛ 2 проектов.

По состоянию на ноябрь 2015 г. в состав ТОФ входили 14 АПЛ. 5 АПЛРБ (2 - проекта 955, 3 - проекта 667БДР) входили в состав 25-й дивизии [4]. 9 АПЛ (5 - проекта 
949А и 4 - проекта 971) входили в состав 10-й дивизии. Все атомные подводные лодки базировались на Камчаткe [8].

ТОФ 1970-1990 гг. решал задачу обеспечения безопасности СССР в Азиатско-Тихоокеанском регионе: с нарастанием угрозы росло напряжение сил флота, интенсивнее неслась боевая служба подводных лодок. Главной ударной силой подводных сил ТОФ были АПЛ, исходя не только из их количества, но и по их боевым возможностям.

Необходимо отметить, 57 (58\%) атомных подводных лодок ТОФ были построены на Дальнем Востоке, что сокращало время ввода в состав флота (АПЛ западной постройки прибывали на ТОФ через 2-7 лет после спуска на воду).
Группировка АПЛРБ ТОФ являлась составляющей Морских стратегических ядерных сил ядерной триады СССР. Наши АПЛРБ решали главную задачу и были надёжным щитом и сдерживающей агрессивные намерения США силой, готовой нанести, как ответный, так и упреждающий удар по вероятному противнику.

Второй по значимости задачей, стоящей перед флотом, была задача максимально осложнить операции надводных сил ВМС США: отслеживать авианосно-ударные (многоцелевые) группы с целью поражения в угрожаемый период, - эту задачу решали АПлРК

Задачи борьбы с надводными кораблями и подводными лодками противника в дальней океанской зоне решали многоцелевые АПЛ.

\section{ЛИТЕРАТУРА}

1. Апальков Ю.В. Корабли ВМФ СССР. Том 1. Часть 1. Подводные лодки. РПКСН и многоцелевые ПЛ. Галея Принт. Санкт-Петербург. 2002. - 90 с.

2. Атомные подводные лодки с баллистическими ракетами типа K-19. Проект 658 (Hotel-I class). Военное обозрение. [Электронный ресурc] - URL. https:// topwar.ru/19890-atomnyepodvodnye-lodki-s-ballisticheskimi-raketami-tipa-k-19-proekt-658-hotel-i-class.html (дата обращения: 11.02.2020).

3. Бережной С.С. Атомные подводные лодки ВМФ СССР и России. Морской исторический альманах «Наваль коллекция» № 7. -2001 г. - 80 с.

4. Корабельный состав и строительство морских стратегических ядерных сил ВМФ РФ на 01.11.2015. [Электронный pecypc] - URL. https://navy-korabel. livejournal.com/114157.html (дата обращения: 15.11.2019).

5. Коробов В.К. Подводный крейсер стратегического назначения. Текст. /В.К. Коробов. // Вестник Российской академии наук. - Т. 66. - №11. - 1027-1031 с.

6. Кузин В.П., Никольский В.И. Военно-морской флот СССР 1945-1991. СПб, Историческое Морское Общество, 1996. - 653 с.

7. Отечественные атомные подводные лодки. Техника и вооружение. Р00 «Техинформ». - 2000 № 5-6. - 80 с.

8. Подводные силы ВМФ России: организация, базирование, состав. [Электронный ресурс] - URL. https://balabin 1712.livejournal.com /10320.html (дата обращения: 20.03.2020).

9. Флот ПЛА СССР. Анатомия создания. [Электронный ресурс] - URL. https://flot.com/blog/flot/(дата обращения: 18.12.2019).

10. 25-я дивизия подводных лодок ТОФ. Военно-технический альманах «Тайфун». Выпуск № 54. 3А0 «СПП0-2». - 2010 г. - 52-60 с.

11. ЦАМО АО ТОФ (Центральный архив МО арх. отд. ТОФ)

(c) Семёнов Виктор Николаевич (viktor_55@mail.ru).

Журнал «Современная наука: актуальные проблемы теории и практики» 